Ingested foreign bodies are common [1] and the most common foreign body found in the upper gastrointestinal tract in adults is food [1,2]. Several endoscopic methods are used for the removal of food boluses. Carefully pushing the bolus into the stomach, and extraction using snares, forceps, Dormia baskets, and suction with a friction-fit adapter, have been employed most frequently [3-5]. We report the use of a loose-grip technique with a Dormia basket to remove food boluses and get past the upper esophageal sphincter.

A 44-year-old man was admitted with an 18-hour history of absolute dysphagia, following a meal. The meal consisted of rice, bread, vegetables, and chicken. Emergency upper gastrointestinal endoscopy revealed a meat bolus, with some vegetable matter, lodged firmly at the lower esophageal sphincter (Figure $\mathbf{1}$ ). All attempts to get past the impaction proved futile and the food bolus could not be dislodged by the use of gentle pressure. Attempts at suction removal of the food bolus using a friction-fit adapter mounted on the endoscope failed. The endoscopist was able to trap the bolus in a Dormia basket and pull it up (Figure 2) but, despite various attempts and maneuvers, it was not possible to get it through the upper esophageal sphincter. The assistant was then asked to loosen the grip of the Dormia basket slightly. Pulling the endoscope and the Dormia basket, the food bolus was then easily removed from the esophagus. Repeat endoscopy did not reveal any abnormality. We have successfully used this technique to remove an impacted food bolus and get past the upper esophageal sphincter in two other patients. An overtube was not used in these patients because the size of the food boluses could not be assessed as they were lying longitudinally and their apparent size (Figure 1) was much smaller than the real size (Figure 2 ). Only after the boluses were trapped in the Dormia basket and pulled up could their real size be ascertained.

\section{Loose-Grip Technique for Removing Large Food Boluses from the Esophagus}

It is common practice for the endoscopist's assistant to tighten the grip on any foreign body that has been trapped in an extraction device. However, because the food boluses were large and because they were trapped with their longest diameter transversely across the esophageal lumen (as in Figure 2 ) they could not be maneuvered past the upper esophageal sphincter. Slightly loosening the grip allowed the boluses to reorient in the longitudinal axis and facilitated their extraction. This method can be useful in the removal of large oval or oblong foreign bodies or food boluses from the upper gastrointestinal tract.

\section{S. P. Misra, M. Dwivedi}

Department of Gastroenterology, Moti Lal Nehru Medical College, Allahabad, India.

\section{References}

${ }^{1}$ Mosca S, Manes G, Martino Ret al. Endoscopic management of foreign bodies in the upper gastrointestinal tract: report of 414 adult patients. Endoscopy 2001; 33: $692-696$

${ }^{2}$ Webb WA. Management of foreign bodies of the upper gastrointestinal tract. Gastroenterology 1988; 94: 204-216

${ }^{3}$ Soehendra N, Binmoeller KF, Seifert H, Schreiber HW, editors. Therapeutic Endoscopy: color atlas of operative techniques for the gastrointestinal tract. Stuttgart; Thieme 1998: 1-12

${ }^{4}$ Saeed ZA, Michaletz PA, Feiner SDet al. A new endoscopic method for managing food impaction in the esophagus. Endoscopy 1990; 22: 226-228

${ }^{5}$ Mamel JJ, Weiss D, Pouagare M, Norda HJ. Endoscopic suction removal of food boluses from the upper gastrointestinal tract using Stiegmann-Goff friction-fit adapter: an improved method for removal of food impactions. Gastrointest Endosc 1995; 41: $593-596$

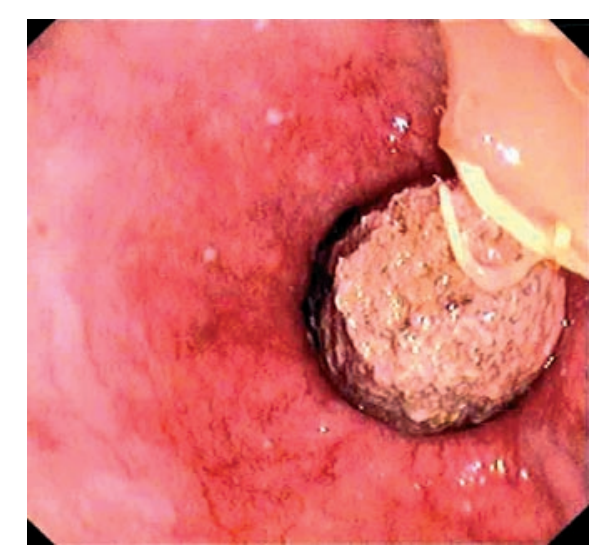

Figure 1 Bolus of chicken meat impacted at the lower esophageal sphincter.

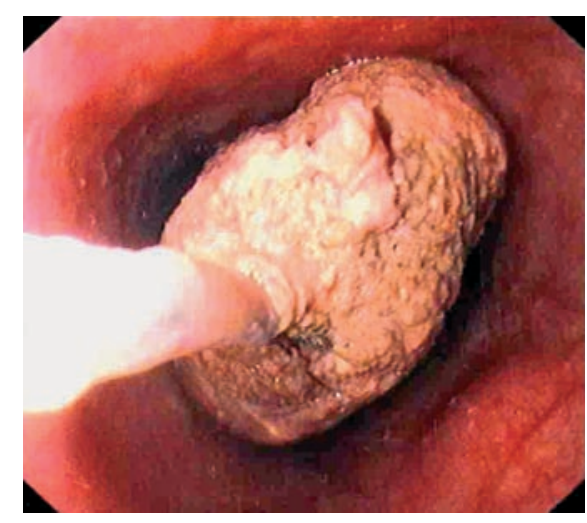

Figure 2 The bolus of chicken is firmly held in the Dormia basket. Note the transverse orientation of the bolus.

\section{Corresponding Author}

\section{S. P. Misra, MD}

Department of Gastroenterology, Moti Lal Nehru Medical College

Allahabad 211001

India

Fax: $\quad+91-532-2611420$

E-mail: spmisra@sancharnet.in 